\title{
Oceanographic flow regime and fish recruitment: reversed circulation in the North Sea coincides with unusually strong sandeel recruitment
}

\author{
Ole Henriksen ${ }^{1}$, Asbjørn Christensen ${ }^{1}$, Sigrún Jónasdóttir ${ }^{2}$, Brian R. MacKenzie ${ }^{2}$, \\ Kristian Ege Nielsen ${ }^{1}$, Henrik Mosegård ${ }^{1}$, Mikael van Deurs ${ }^{1, *}$ \\ ${ }^{1}$ National Institute for Aquatic Resources - Section for Marine Living Resources, Technical University of Denmark, \\ Kemitorvet, 2800 Kgs Lyngby, Denmark \\ ${ }^{2}$ National Institute for Aquatic Resources - Section for Oceans and Arctic, Technical University of Denmark, Kemitorvet, \\ 2800 Kgs Lyngby, Denmark
}

\begin{abstract}
The search for environmental descriptors of fish stock production is ongoing. Although numerous correlations between environmental variables such as food abundance or sea surface temperature have been proposed in the past, few are operational in a fisheries management context today. Reasons for this may include many - but spurious - correlations, the use of higher-level climate-change indicators, and misconceived perception of causal relationships. In the present study, we demonstrate how modelled oceanographic data describing local conditions, combined with a simple probabilistic risk assessment, can be used to forecast fish recruitment. We used the lesser sandeel Ammodytes marinus in the North Sea as an example, and focussed on the circulation patterns experienced by the first-feeding larvae on the Dogger Bank. A strong link between the net direction of water transport at the surface and unusually strong year-classes of sandeel was found. For example, the most extreme recruitments only took place in years with a particular type of flow regime in February, which may be associated with the occasional reversals of the North Sea circulation. Using risk ratios, we show the potential for using flow regime in probabilistic short-term forecasts of unusually strong year-classes. Lastly, we propose a hypothesis for recruitment in sandeel which could be extended to other species, and thereby contribute to future studies of predictors in recruitment forecasting.
\end{abstract}

KEY WORDS: Recruitment - Flow - First feeding - Match-mismatch - Short-term forecast · North Sea $\cdot$ Sandeel $\cdot$ Ammodytes marinus $\cdot$ Circulation

\section{INTRODUCTION}

The search for robust environmental drivers to be incorporated into fish stock forecasting, and thus to guide resource management decisions, has been ongoing for decades (Hutchings 1992). Yet, examples of effective integration of environmental variability into stock assessments, forecasting, and management are rare (Walters \& Collie 1988, Myers 1998, Skern-Mauritzen et al. 2016, Payne et al. 2017). However, recent advances in oceanographic model out-

*Corresponding author: mvd@aqua.dtu.dk puts and a demand for ecosystem-based approaches in fisheries management have stimulated the search for new candidate drivers of fish stock dynamics and alternative ways of making short-term forecasts (Stocker \& Hilborn 1981, Nerger et al. 2014, Collie et al. 2016, Payne et al. 2017).

The lack of successful applications of environmental predictors (e.g. physical and biological) to date may be partly due to the strong emphasis placed on the stock-recruitment (S-R) relationship (Ricker 1954), which assumes that recruitment variability (i.e. where

() The authors 2018. Open Access under Creative Commons by Attribution Licence. Use, distribution and reproduction are unrestricted. Authors and original publication must be credited. 
recruitment is understood as the number of young-ofthe-year individuals at the life phase transition from larvae to juveniles; ICES 2018) is primarily explained by the biomass of the reproductively active segment of a stock, also termed the spawning stock biomass, and thus any environmental influence must therefore be secondary (Myers 1995, Myers \& Barrowman 1996). However, modelled S-R relationships for individual stocks are often weakly supported by the data, due to high inter-annual variability in recruitment, in combination with relatively short time-series (Fogarty et al. 1991, Olsen et al. 2011, Szuwalski et al. 2015). Established correlations are therefore often quite weak, and tend to decompose or change over time (Myers 1998, Skern-Mauritzen et al. 2016).

The perception that recruitment is a function of the biological and physical oceanography dates back a century (Hjort 1914, 1926). Corollaries from this work have since given rise to hypotheses, such as the 'match-mismatch' hypothesis (Cushing 1975, 1990), which build on the realization that biological and physical processes might be complementary and emphasize the importance of matches in time and space between the early life stages and the availability of food and the 'right' physical conditions. In a recent meta-analysis, Vert-pre et al. (2013) found that although some stocks showed strong S-R relationships, net population increases for the majority of stocks were driven by environmental regimes.

Examples of significant correlations between recruitment and planktonic food resources are common in the literature (e.g. Beaugrand et al. 2003, van Deurs et al. 2009, Burrow et al. 2011, Kristiansen et al. 2011). The fate of fish larvae and food sources are to a large extent influenced by the same oceanographic features, and yet the local oceanographic processes are often neglected in these studies or replaced by higher-level climate indicators such as average temperature or teleconnection indices like the North Atlantic Oscillation (NAO, an index of the predominant air circulation patterns over the North Atlantic) (Arnott \& Ruxton 2002, Solow 2002).

The purpose of the present study was to explore the potential for using advanced oceanographic model output in short-term forecasts of fish stock production (i.e. recruitment), which we investigated using a well-studied North Sea case. The ecologically and economically important lesser sandeel Ammodytes marinus stock on the Dogger Bank (DB) in the central North Sea is an example of a fish stock in which recruitment dynamics drive most of the population variability and catch opportunities. This stock is a typical 'boom-and-bust' type of stock (Schwartzlose et al.
1999), characterized by dramatic fluctuations and occasional unusually strong year-classes that sustain a large fishery in the following years. Hence, the ability to predict the coming of an exceptionally strong yearclass is of major importance (de Moor et al. 2011). The recruitment of sandeel has been linked to both food abundance and climate indicators, such as sea surface temperature (SST) and the NAO (Arnott \& Ruxton 2002, van Deurs et al. 2009, Régnier et al. 2017, Lindegren et al. 2018). With respect to food availability, in particular the temporal match-mismatch between occurrence of first-feeding larvae and the abundance of the 2 largest copepod species in the North Sea, Calanus finmarchicus and C. helgolandicus, has been stressed (Arnott \& Ruxton 2002, van Deurs et al. 2009, Régnier et al. 2017). Simulation studies of hydrodynamic larval drift and circulation processes that affect larval growth have also been carried out (Christensen et al. 2007, Gurkan et al. 2012), but studies on the connection between local oceanographic events and inter-annual variability in sandeel recruitment do not exist.

The general flow regime of the North Sea can be described as a counterclockwise circulation produced by prevailing southwesterly winds, which occasionally reverses with easterlies. This occasional shift from the predominant counterclockwise circulation to other regimes can include a large-scale gyre flowing in the opposite direction over the whole North Sea or multiple smaller-scale gyres with alternating flow directions and even temporary circulation halts (Kauker \& von Storch 2000, Sündermann 2003, Sündermann \& Pohlmann 2011). Changes in the physical setting affect fish production, especially for forage fish that display boom-and-bust dynamics (Fréon et al. 2005). For example, upwelling events driving the production of Pacific sardine stocks off the coast of Central America (Rykaczewski \& Checkley 2008) are strongly linked to certain types of ocean circulation patterns. Another example is the Norwegian spring spawning herring, where the physical conditions of the Norwegian Coastal Current determine survival and growth of the larvae as they drift toward the nursery grounds in the Barents Sea (Skagseth et al. 2015).

During a preliminary investigation, it was observed that the largest sandeel recruitment event on record coincided with a circulation shift in the northwest Atlantic during the winter of 1996, first mentioned by Greene \& Pershing (2003) and later coupled to possible circulation reversals in relation to settlement dynamics of 2 species of flatfish in the North Sea (Lacroix et al. 2013, Tiessen et al. 2014). While many 
studies have flagged hydrodynamics as playing various roles for sandeel recruitment involving different biophysical levels and larval life stages (Berntsen et al. 1994, Proctor et al. 1998, Gallego et al. 2004, Christensen et al. 2007, Gurkan et al. 2013), they all agree on the notion that at least the earliest life stages, or first-feeding larvae, should be considered as passive tracers whose fate is dictated by the ocean currents. Although sandeel larvae develop active swimming abilities before they metamorphose at a length of $\sim 40 \mathrm{~mm}$, it is assumed that they generally follow current surface flow until settlement (Christensen et al. 2008). The drifting phase lasts from 13 mo (i.e. Februray to April) (Wright \& Bailey 1996, Conway et al. 1997, Jensen et al. 2003).

We therefore hypothesized that unusual strong yearclasses of DB sandeel are associated with certain types of flow regimes during the early parts of the drifting period when first-feeding larvae are most abundant. Flow regimes were quantified using original output from an oceanographic model (HIROMB-BOOS), and the period of first feeding was examined from hatch dates estimated using larval otoliths. Subsequently, the oceanographic output was subjected to a cluster analysis to tease apart different types of flow regimes, before relating these to sandeel recruitment. To test the usefulness of flow regimes in short-term forecasting of strong year-classes, we used a probabilistic approach. This approach, also known as the risk-ratio analysis, is widely used in risk assessments (Wilson \& Crouch 1987), but rarely applied in fisheries science (but see Mantzouni \& MacKenzie 2010 and Skagseth et al. 2015). Nevertheless, it may be suitable for detecting mechanisms associated with infrequent extreme year-classes, as seen for our case stock. We applied this approach to the flow regime data that resulted from the cluster analysis, as well as to other environmental variables previously suggested to be influencing sandeel recruitment. This comparative approach not only allowed us to rank the performance of the different recruitment predictors, but it also provided a basis for discussing possible causal mechanisms.

\section{MATERIALS AND METHODS}

\section{Oceanographic data}

We inspected 3 papers (i.e. Kauker \& von Storch 2000, Sündermann 2003, Sündermann \& Pohlmann 2011) in order to identify an oceanographic timeseries of flow regimes that captured the essentials of the Central North Sea water circulation system as well as the transport of water over the DB, where the most important sandeel fishing grounds are located. Based on these studies, we settled on a transect that followed the $50 \mathrm{~m}$ depth contour, along the northern edge of the $\mathrm{DB}$, stretching from the centre of the North Sea to 60 nautical miles (n miles) from the UK coastline $\left(0.0^{\circ} \mathrm{E}, 55.5^{\circ} \mathrm{N}\right.$ to $\left.4.0^{\circ} \mathrm{E} 56.0^{\circ} \mathrm{N}\right)$, the latter to avoid the influence of the Scottish coastal current (i.e. Brown et al. 1999) (Fig. 1). Based on the assumption that first-feeding larvae are passive drifters distributed in the water column (e.g. Christensen et al. 2007), hourly values of the net flow of surface water (0-15 $\mathrm{m}$ depth) were then derived by summing up 3D water fluxes from an oceanographic model (described in more detail below).

Otolith-based estimates of hatch dates in the Shetland sandeel population, early-stage larvae captured over the DB by the Continuous Plankton Recorder (CPR), and peak larval survival estimated by individual-based modelling (Wright \& Bailey 1996, Gurkan et al. 2013, Lynam et al. 2013) seem to indicate that February and March covers the most important period for first-feeding larvae; thus we chose to focus on these months in the data analysis (this assumption was tested later in the present study; see 'Estimation of hatch dates', below).

The oceanographic data were provided by the Danish Meteorological Institute (DMI) and are a validated hindcast (1990-2013) produced by the North Sea-Baltic Ocean Model (HBM Model) in the operational setup used by DMI (http://ocean.dmi.dk/ models/hbm.uk.php). The model is a 3D ocean circulation model, where the vertical flow assumes hydrostatic balance and incompressibility of sea water, and horizontal transport is modelled using the Boussinesq approximations (Smagorinsky 1963, Canuto et al. 2002, Berg \& Poulsen 2012). The horizontal resolution (grid spacing) was $6 \mathrm{n}$ miles, which is a standard resolution used by DMI for coarse-scale applications, and has previously been used to model fish larval drift in the North Sea and water fluxes between the North Sea and the Baltic Sea (e.g. She et al. 2007, Gurkan et al. 2013, Ulrich et al. 2017). The main consequence of this relatively coarse grid spacing is the potential risk of failing to capture the full effect of small-scale eddies and the risk of exaggerating the wind effect. However, in the present study, we were only interested in the trends in net flow averaged across $300 \mathrm{~km}$ wide transects (i.e. the geographical scale of interest is 27 times larger than the model resolution), where small-scale processes are likely to be averaged out as fluctuations along the transect. The model was forced by atmospheric data from a numer- 


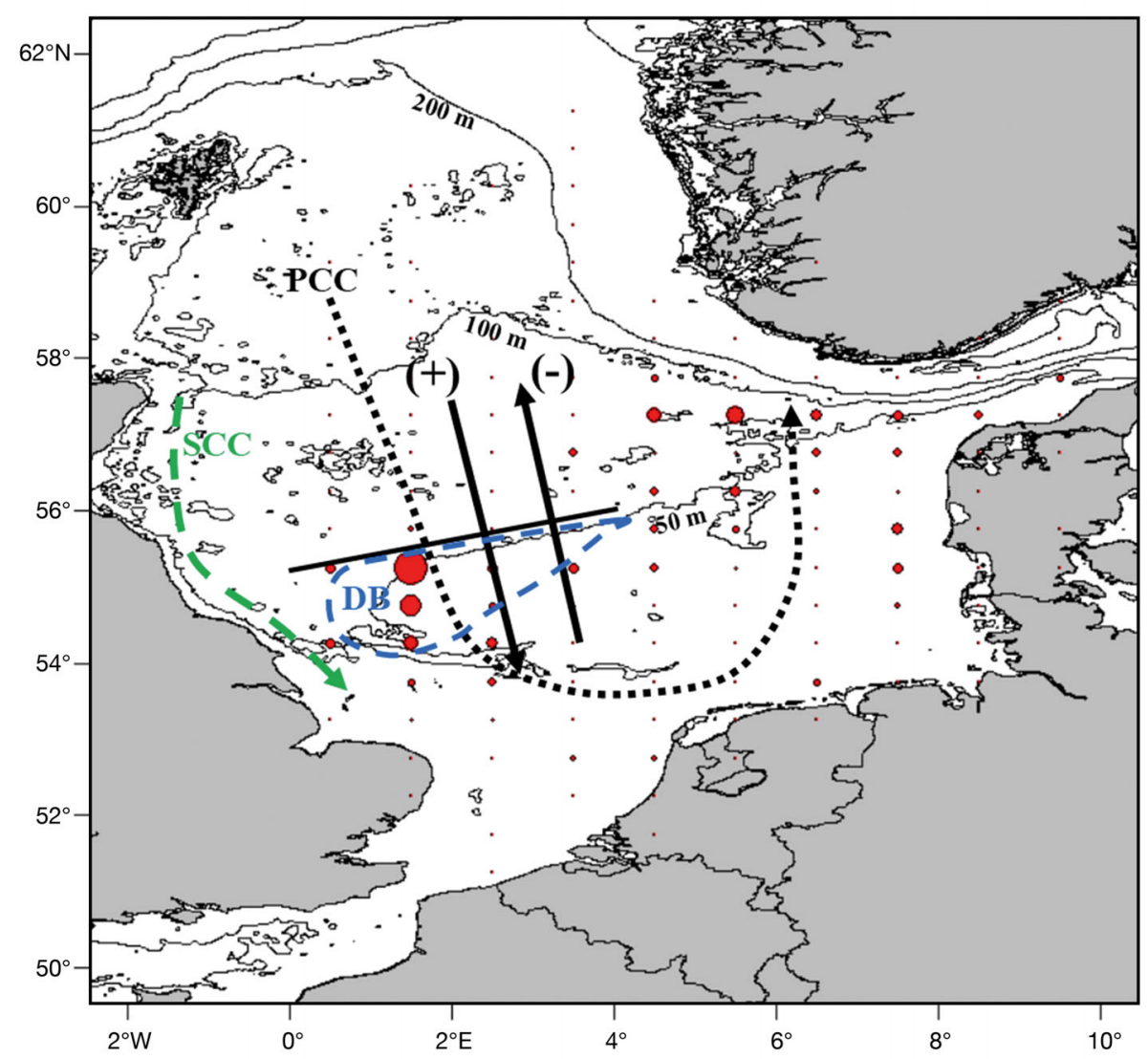

Fig. 1. Study area, showing the position of the transect used to extract flow data from the oceanographic model (thick black line). The large black arrows with associated negative and positive signs, respectively, describe how the transport of water intercepts the transect in a northerly direction when data values are negative and in a southerly direction when values are positive. The 50, 100, and $200 \mathrm{~m}$ depth contours are marked, showing how the transect follows the $50 \mathrm{~m}$ contour on the northern edge of the Dogger Bank (DB, indicated by a blue dashed line enveloping an area immediately south of the transect). The predominant circulation current (PCC) of the central North Sea is depicted by the dotted arrow, while the Scottish Coastal Current (SCC) is depicted with a green dashed arrow. The surface area of the red bubbles represents the relative distribution of sandeel catches for the period 2003-2016 (ICES 2016a)

ical weather prediction model, High Resolution Local Area Model (HIRLAM, http://hirlam.org/), with $10 \mathrm{~m}$ wind fields, sea level pressure, temperature, humidity, and cloud cover. At open model boundaries between Scotland and Norway, and in the English Channel, we used tide surges from a barotropic model of the North Atlantic (Dick et al. 2001). All other model variables at open boundaries were set to monthly climatological values. The freshwater daily river runoff data come from the operational hydrological model HBV run by the Swedish Meteorological Hydrological Institute (Bergström 1992) and observations made by German Bundesamt für Seeschifffahrt und Hydrographie. The hindcast period (1990-2013) was limited by the overlap of applied forcing data sets.

In the present study, we expressed the net flow of water across the transect as the signed (i.e. \pm ) accu- mulated length $(\mathrm{km})$ of water that has moved through the transect since time 0 , averaged across the surface of the transect (where ' + ' indicates water movement from north to south and ' - ' indicates the opposite movement, from south to north). Time 0 was either 1 February or $1 \mathrm{March}$, and the final dataset consisted of hourly values for all of February and March, respectively. To get from length of water to the volume of water, we must multiply by the dimensions of the transect surface area, which was $300 \mathrm{~km}$ (transect length) times $0.015 \mathrm{~km}$ (transect depth), and the hourly average transport rate can be derived from the volume at time $h$ minus the volume at time $h$ - 1. However, in relation to the present study, the length of water was found to be the most useful unit, as it offers a direct approximation of the scale of potential horizontal transportation of passively drifting biological particles (such as fish larvae or copepods). 


\section{Identification of flow regimes using principal component analysis and hierarchical clustering}

To identify distinct annual and monthly flow regimes, we carried out a principal component analysis (PCA) on hourly values of the accumulating water transport across the selected transect. PCA is a useful statistical signal-processing technique to reduce the multi-dimensionality of datasets for pattern recognition. The PCA algorithm constructs principal components (PCs) obtained as linear combinations of the original variables, where the first PC is allowed to have the largest possible variation in the data, and the second PC is estimated under the assumption of being orthogonal to the first $\mathrm{PC}$ and to have the largest possible variance, and so forth for other additional PCs that might be important (see Abdi \& Williams 2010 for details). In order to choose the correct number of PCs to be kept in the analysis, we used a scree test (Cattell 1966), which is a graphical detection of a bend in the distribution of the successive variance explained.

Data from February and March were treated in 2 separate PCAs, which assigned each year in the study period to clusters, each of which represented distinct hydrodynamic patterns (hereafter referred to as flow regimes). The Euclidean distances between years were computed from the projection of years on the PCs, and subsequently a hierarchical clustering analysis was conducted. We used the Ward linkage method (Ward 1963), which has a minimum variance criterion that minimizes the total within-cluster variance. For each step, we identified a pair of clusters which leads to a minimum increase in total withincluster variance when merged. The PCA and the hierarchical clustering analysis were implemented in the R-packages 'PTA-k' (Leibovici 2010) and 'ade4' (Chessel et al. 2004).

\section{Sandeel recruitment}

As a measure of sandeel recruitment on the DB, we used the number of young sandeel in July (age 0) as estimated by the International Council for the Exploration of the Sea (ICES) for Management Area 1 (ICES 2016a). These recruitment estimates are produced by a stochastic multispecies stock assessment model (Lewy \& Vinther 2004) and are essentially back-calculated in the model from the number of $1 \mathrm{yr}$ old sandeel estimated by the model in the following year using the natural mortality for age 0 sandeel in the second half year (ICES 2016a). Prior to the update of recruitment time-series in March 2017, input to the stock assessment model used by ICES was changed. We therefore included recruitment time-series from before and after the 2017 update (ICES 2016b, 2018).

\section{Estimation of hatch dates}

To identify and confirm the important months (i.e. February/March; Gurkan et al. 2013, Lynam et al. 2013) of first-feeding larvae in the DB area, we derived hatch dates from sandeel otoliths taken from larvae caught on the DB in 2006, 2008, and 2009. All larvae samples were collected between 17 and 22 April. The larvae were caught with a $1 \mathrm{~m}$ MethotIsaac-Kidd (MIK) net, then frozen at sea and later thawed and preserved in ethanol. Three MIK samples were randomly selected from each year (9 samples in total). From each sample, 20 larvae were subsampled using a stratified sampling procedure to cover the full length distribution. Otoliths were dissected from the larvae under polarized light, imbedded in thermoplastic cement, and then photographed under a microscope. Daily increment widths were measured from the central primordium to the otolith edge, but not all increments were visible. Hence, the age in days was determined by dividing the distance from yolk sac absorption to the otolith edge by the mean daily increment width and then adding $12 \mathrm{~d}$ to account for the yolk sac period (Wright 1993, Wright \& Bailey 1996). The distance along the axis of fastest growth from the primary primordium to the point of yolk sac absorption was assumed to be $20 \mu \mathrm{m}$ (Wright 1993). A linear age-length relation derived from the subsampled otoliths was then used to convert the length distribution in the original MIK sample to a hatch date distribution. Lastly, each hatch date distribution was corrected for natural mortality. Daily mortality rates ranging between 0.042 and 0.07 (Fujiwara et al. 1990, Régnier et al. 2017) have previously been assumed, and we therefore investigated the sensitivity of mortality. In order to make our results directly comparable to those of Wright \& Bailey (1996), we adopted a mortality rate of 0.07 , but we also included high (0.12) and low (0.01) mortality rates by simply increasing mortality by $\sim 100 \%$.

\section{Quantifying and comparing the performance of different predictors of recruitment}

Previous studies have reported positive relationships between sandeel recruitment and Calanus 
copepods and negative relationships with SST and the NAO (Arnott \& Ruxton 2002, van Deurs et al. 2009, Régnier et al. 2017, Lindegren et al. 2018). In the present study, we wanted to re-investigate all of these recruitment predictors together with our new oceanographic predictor. Information about the abundance of $C$. finmarchicus and $C$. helgolandicus were acquired from the CPR programme. These data were provided by the Sir Alister Hardy Foundation for Ocean Science (SAHFOS), and came as monthly indices calculated specifically for Management Area 1 that covers the DB (ICES 2016b). The NAO was downloaded as station-based monthly values from the Hurrel data base: https://climatedataguide.ucar. edu/climate-data/hurrell-north-atlantic-oscillationnao-index-station-based. SST was downloaded from the Hadley Centre observational database as monthly values in a $1 \times 1^{\circ}$ grid. For the present study, we used the average SST for an area defined as $1-3^{\circ} \mathrm{E}$ and $54-55^{\circ} \mathrm{N}$. Only data from February and March were included in the analysis to match the period of first feeding and the oceanographic data (see explanation above). One exception to this rule was NAO, where we used an early (mean NAO for the period from December to February) and a late winter index (mean NAO for the period from January to March) instead of monthly values.

In order to compare the different candidate recruitment predictors, we computed the risk-ratio (RR) as in Mantzouni \& MacKenzie (2010):

$$
R R=\frac{G /(g+G)}{C /(c+C)}
$$

where $G$ is the number of years where favourable environmental conditions coincided with good recruitment (i.e. unusually strong year-classes), $g$ is the number of years where favourable conditions did not coincide with good recruitment, $C$ is the number of years where unfavourable conditions coincided with good recruitment, and $c$ is the number of years where unfavourable conditions did not coincide with good recruitment. In cases where $G$ or $C$ was 0 , we replaced 0 with $1 / 24$, since we have 24 observations in total.

Since the intention was to forecast the most extreme recruitment events rather than the stock trends, good recruitment was defined as recruitments that exceeded the mean of the time-series plus $1 \mathrm{SD}$. This approach suited its purpose and captured the distinct spikes in the recruitment time series, which are of particular importance in relation to managing boom and bust stocks (de Moor et al. 2011). Based on the previously mentioned reports of a positive relationship between sandeel recruitment and Calanus copepods and negative relationships for SST and NAO, we defined favourable conditions in relation to each of those predictors as values either above or below the time-series mean $\pm 1 \mathrm{SD}$. RR $>1$ indicates that the probability of observing good recruitment when the environmental condition is expected to be favourable is higher than the probability of observing good recruitment when the environmental condition is unfavourable. Hence, high values of RR were considered indicative of high performance in relation to recruitment forecasting. We also applied the same RR approach to derive RR values for the opposite question; i.e. the relative probability of seeing less than good recruitment when environmental conditions are favourable (i.e. $R R=$ $[c /(C+c)] /[g /(G+g)])$. In this test, low RR values were considered indicative of high performance. To distinguish between the 2 different applications of the $R R$ equations, we used $R_{1}$ and $R_{2}$ to label the former and latter application, respectively. Finally, we obtained p-values by applying the chi-squared test of independence to a $2 \times 2$ contingency table $\left[\begin{array}{cc}G & g \\ C & C\end{array}\right]$. The p-values refer to the null hypothesis that the 2 categorical variables (environmental condition and recruitment) are independent.

\section{RESULTS}

The net flow of water across the selected transect (analysed for February and March) went from being almost consistently positive (i.e. running in a northsouth direction) or negative (i.e. running in a southnorth direction), through highly variable, alternating between positive and negative, to nearly stagnant (Fig. 2A,C). The classification of clusters was mainly driven by the overall direction of the net flow (positive or negative), but the temporal development of the trajectories was also important. Division of years into clusters was based on 2 PCs (PC1 and PC2, Fig. A1 in the Appendix), together explaining 93.0 and $94.5 \%$ of the total variation in February and March, respectively (Fig. 2B,D). These clusters captured certain types of flows: (1) unidirectional flow and relatively large negatively or positively signed net flow (advection), (2) bidirectional flows associated with negatively or positively signed low net flow (retention), (3) relatively weak or stagnant flow that suddenly shifts to a negatively or positively signed directional flow of higher net flow (shifting flow), and 

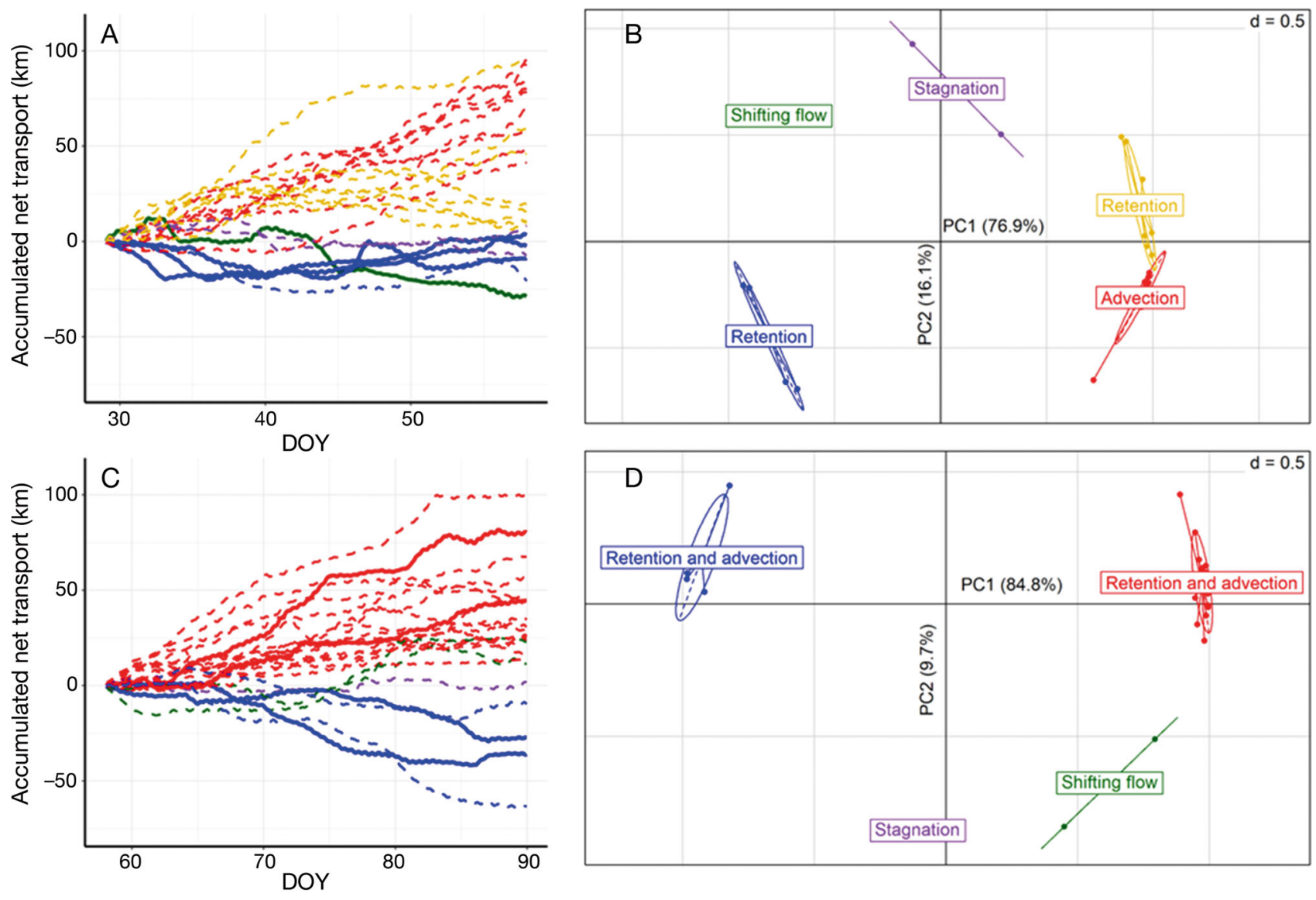

Fig. 2. Flow trajectories of water moving across a surface transect in the North Sea in (A) February and (C) March (see Fig. 1 for the position of the transect). The net transport of water ( $y$-axis) at any point in time ( $x$-axis) is expressed as the accumulated signed (i.e. \pm ) volume of water that has moved across the transect since the start of the month. Hence, the accumulated net transport starts at 0 in each month. Each line represents a specific year within the study period (1990-2013). Good recruitment years are highlighted with solid thick lines (see Fig. 4 for good recruitment years). Colors correspond to clusters assigned by the principal component analysis ( $\left.\mathrm{PCA}_{i} \mathrm{~B}, \mathrm{D}\right)$ with 2 principal components, PC1 and PC2, together explaining 93.0 and $94.5 \%$ of the total variability and identifying 5 and 4 clusters for (B) February and (D) March, respectively. PC1 ( $x$-axis) describes a gradient from negative to positive values of net flow, and PC2 ( $y$-axis) describes the temporal development of the flow trajectory. A label describing the type of flow captured by each cluster is provided in boxes. DOY: day of the year

(4) relatively weak flow alternating between positive and negative flow centered around 0 (stagnant).

PC1 explained most of the variation (76.9 and $84.8 \%$ for February and March, respectively) and discriminated among the types of flows listed above, making a distinction between years of predominantly positive net flow and years of predominantly negative net flow, which represented 2 overarching clusters in both February and March (Fig. 3) and are hereafter referred to as negative and positive flow regimes. However, each flow trajectory was also associated with a temporal behaviour over the transect, for example whether a flow trajectory had a flow with a directional motion, either a continuous or oscillating motion over the transect, or a motion with close to 0 flow in any direction. This temporal behaviour was captured by the second PC2, explaining 16.1 and $9.7 \%$ of the variation in February and March, respectively (Fig. 2). The years also had correlations with and total contributions to each PC that supported this (Figs. A2 \& A3). The PCA identified 5 different types of flows in February, but only 4 in March, where the analysis failed to distinguish between advection and retention (Figs. $2 \& 3$ ).

The year 1994 differed from all other years (in February), as it went from almost stagnant to the highest continuous negative flow observed; thus it is essentially an intermediate between the 'stagnant' and 'retention/advection' flow types, which is also why the analysis places this year in its own sub-cluster labelled 'shifting flow' (Figs. 2 \& 3, green). Another outlier was 1991 (March), characterized by an ex- 

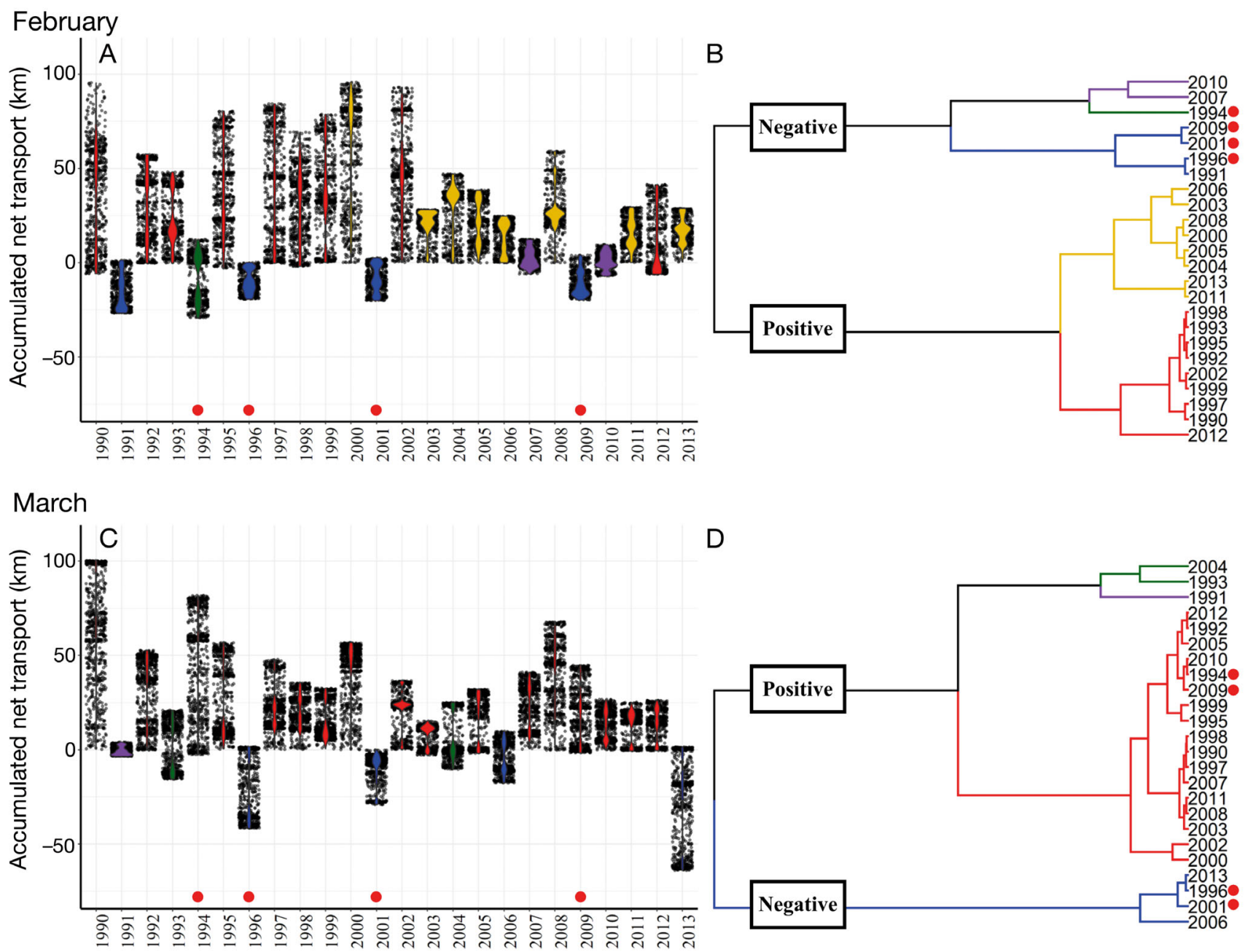

Fig. 3. (A,C) Hourly values of accumulated net transport depicted by year (each small black dot represents a single hourly transport value) and $(B, D)$ dendrograms of the hierarchical clustering, for February $(A, B)$ and March $(C, D)$. Colouration appears in the time-line graphs in panels $\mathrm{A}$ and $\mathrm{C}$ at high densities of hourly transport values (at very high densities, the coloured area spreads out horizontally; note also that colours are comparable to the dendrograms in B and D and to the colour schemes used in Fig. 2A). The dendrograms split years into 2 overarching clusters: one with predominantly positive and one with predominantly negative flow regimes. The overarching clusters are split further into other sub-clusters. Red bullet points highlight years with distinct recruitment spikes (see Fig. 4 for good recruitment years)

tremely stagnant flow and net transport close to 0 (Figs. 2 \& 3, purple).

Also noteworthy was the decreasing trend in net flow in February, where all years (except 2000) assigned to the cluster of positive 'retention' flows appeared after 2002. Likewise, only 1 year after 2002 was assigned to the cluster of positive 'advection' flows (2012, the weakest among the advection years). Hence, it appears that a shift in the winter oceanography in February from an advection-dominated system to a retention-dominated system occurred around 2002 (Fig. 3A).

Good recruitment (i.e. recruitment $>$ mean $+1 \mathrm{SD}$ ) was observed in 1994, 1996, 2001, and 2009 (Fig. 4). In February, all 4 years with good recruitment were assigned to the same overarching cluster consisting of negative flow regimes. However, only 1996 and 2001 were assigned to negative flow regimes in both February and March (Fig. 3). Furthermore, 3 out of the 4 good recruitment years were assigned to the same sub-cluster of negative 'retention' flows. Only 1994 was assigned differently and placed (as the only year in the February time-series) to a sub-cluster labelled 'shifting flow' (the flow phenomenon of 1994 is described in more detail above, this subsection).

According to the analysis of daily increments in larval otoliths, hatching was mainly confined to March. The earliest hatching occurred on Day 53 (22 February) and the last hatching on Day 83 (24 March). Mean time of hatching also varied between years (by ca. 10 d). Hatching in February was only observed in 2009, whereas in 2006 and 2008 all hatching took 


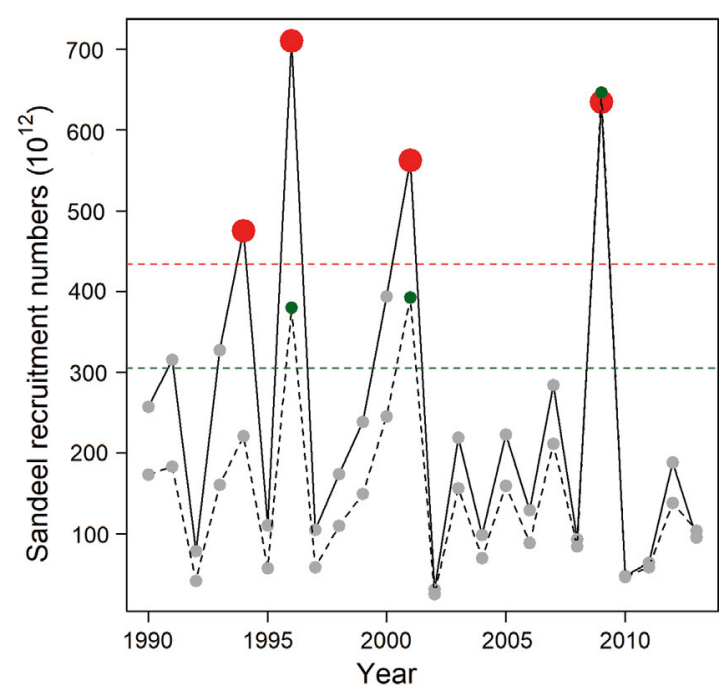

Fig. 4. Sandeel recruitment. Two recruitment time-series are presented: ICES (2016a) (solid line) and ICES (2016b) (black dashed line) (see 'Materials and methods' for details). Good recruitment years (unusual recruitment spikes extending beyond the dashed line) are highlighted with red bullet points (ICES 2016a) or green bullet points (ICES 2016b). Red and green dashed lines: corresponding mean $( \pm 1 \mathrm{SD})$

place in March (Fig. 5). The sensitivity analyses showed that mortality did not have a substantial effect on the hatching distributions. A given percentage hatching was reached earlier with increased mortality, but the maximum difference between the low and high mortality scenario was $5 \mathrm{~d}$ (Fig. 5).

In the first $R R$ test $\left(R_{1}\right)$, the flow regime in February performed better than all other recruitment predictors. In fact, the $\mathrm{RR}_{1}$ values computed for the flow

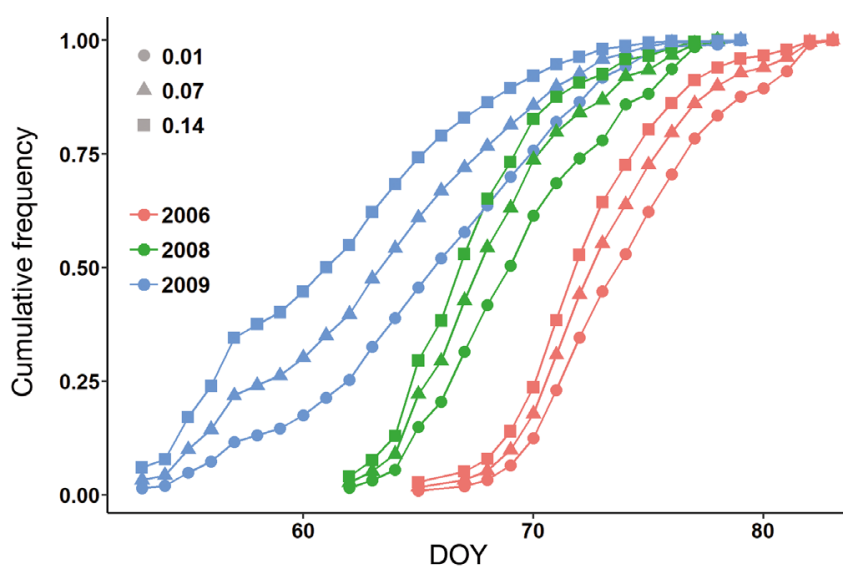

Fig. 5. Cumulative hatch-day frequency. Hatch dates were estimated from larval length distribution and the age-length relationship found by otolith daily increment analysis for sampled years: 2006 (red), 2008 (green), and 2009 (blue). Hatch frequencies were corrected for cumulative mortality assuming different mortality rates of 0.01 (circles), 0.07 (triangles) and $0.14 \mathrm{~d}^{-1}$ (squares). DOY: day of the year

regime in February suggested that the probability of observing the combination of good recruitment and a negative flow regime was 243 times higher than the probability of observing the combination of good recruitment and a positive flow regime. In support of this result, the chi-squared test revealed a significant relationship between the distribution of recruitment and the distribution of flow regime in February (i.e. rejecting the null hypothesis of independence: $\chi^{2}=$ 7.91, $\mathrm{p}=0.005$; Table 1). In comparison, the corresponding $\mathrm{RR}_{1}$ for the negative flow regimes in March and Calanus finmarchicus in February was only 5.00

Table 1. Risk ratios (RR) and chi-squared test of independence for various sandeel recruitment predictors. $G, g, C$, and $c$ correspond to the values entered into the RR formulas $\left(\mathrm{RR}_{1}\right.$ and $\mathrm{RR}_{2}$ ) (see 'Materials and methods: Quantifying and comparing ...' for more details). Note that high performance of a predictor is indicated by large $R_{1} R_{1}$ values and small $R R_{2}$ values. Chi-squared statistics and $\mathrm{p}$-values refer to the null-hypothesis that the 2 categorical variables (environmental condition and recruitment) are independent. The tests were performed on $2 \times 2$ contingency tables $\left[\begin{array}{cc}G & g \\ C & C\end{array}\right]$. NAO: North Atlantic Oscillation, SST: sea surface temperature

\begin{tabular}{|c|c|c|c|c|c|c|c|c|}
\hline Environmental predictor & $G$ & $g$ & $C$ & C & $\mathrm{RR}_{1}$ & $\mathrm{RR}_{2}$ & Chi-squared & $\mathrm{p}$ \\
\hline Negative flow regime (February) & 4 & 3 & 0 & 17 & 243.43 & 0.43 & 7.91 & 0.005 \\
\hline Negative flow regime (March) & 2 & 2 & 2 & 18 & 5.00 & 0.55 & 1.50 & 0.221 \\
\hline High Calanus helgolandicus abundance (February) & 0 & 2 & 4 & 18 & 0.11 & 1.20 & 0.00 & 1.000 \\
\hline High C. helgolandicus abundance (March) & 1 & 2 & 3 & 18 & 2.33 & 0.78 & 0.00 & 1.000 \\
\hline High C. finmarchicus abundance (February) & 2 & 0 & 2 & 20 & 10.78 & 0.02 & 5.35 & 0.021 \\
\hline High C. finmarchicus abundance (March) & 1 & 1 & 3 & 19 & 3.67 & 0.58 & 0.11 & 0.741 \\
\hline Low NAO (February) & 1 & 2 & 3 & 18 & 2.33 & 0.78 & 0.00 & 1.000 \\
\hline Low NAO (March) & 2 & 3 & 2 & 17 & 0.67 & 0.67 & 0.81 & 0.369 \\
\hline Low SST (February) & 1 & 2 & 3 & 18 & 2.33 & 0.78 & 0.00 & 1.000 \\
\hline Low SST (March) & 1 & 2 & 3 & 18 & 2.33 & 0.78 & 0.00 & 1.000 \\
\hline
\end{tabular}


and 10.78, respectively (ranking third and second best), and the distributions of recruitment and flow regime were independent (i.e the null-hypothesis of independence could not be rejected). In the second $\mathrm{RR}$ test $\left(\mathrm{RR}_{2}\right), C$. finmarchicus in February performed best $\left(\mathrm{RR}_{2}=0.02, \chi^{2}=5.35, \mathrm{p}=0.021\right.$; Table 1$)$. For example, the relative probability of observing less than good recruitment in combination with a high abundance of $C$. finmarchicus was very low. However, it should be noted that only 2 years qualified as high C. finmarchicus abundance years (1994 and 2009). Time-series of $C$. helgolandicus, C. finmarchicus, NAO, and SST are presented in Fig. 6.

\section{DISCUSSION}

\section{Circulation patterns in the North Sea}

The common circulation in the North Sea is counterclockwise, produced by prevailing south-westerly winds (Sündermann 2003, Sündermann \& Pohlmann 2011), but occasionally the flow direction is reversed (i.e. clockwise circulation). According to reports by Greene \& Pershing (2003) and Tiessen et al. (2014), such an event took place in 1996. In the present study, the year 1996 was assigned to the overarching cluster encapsulating negative flow regimes in both February
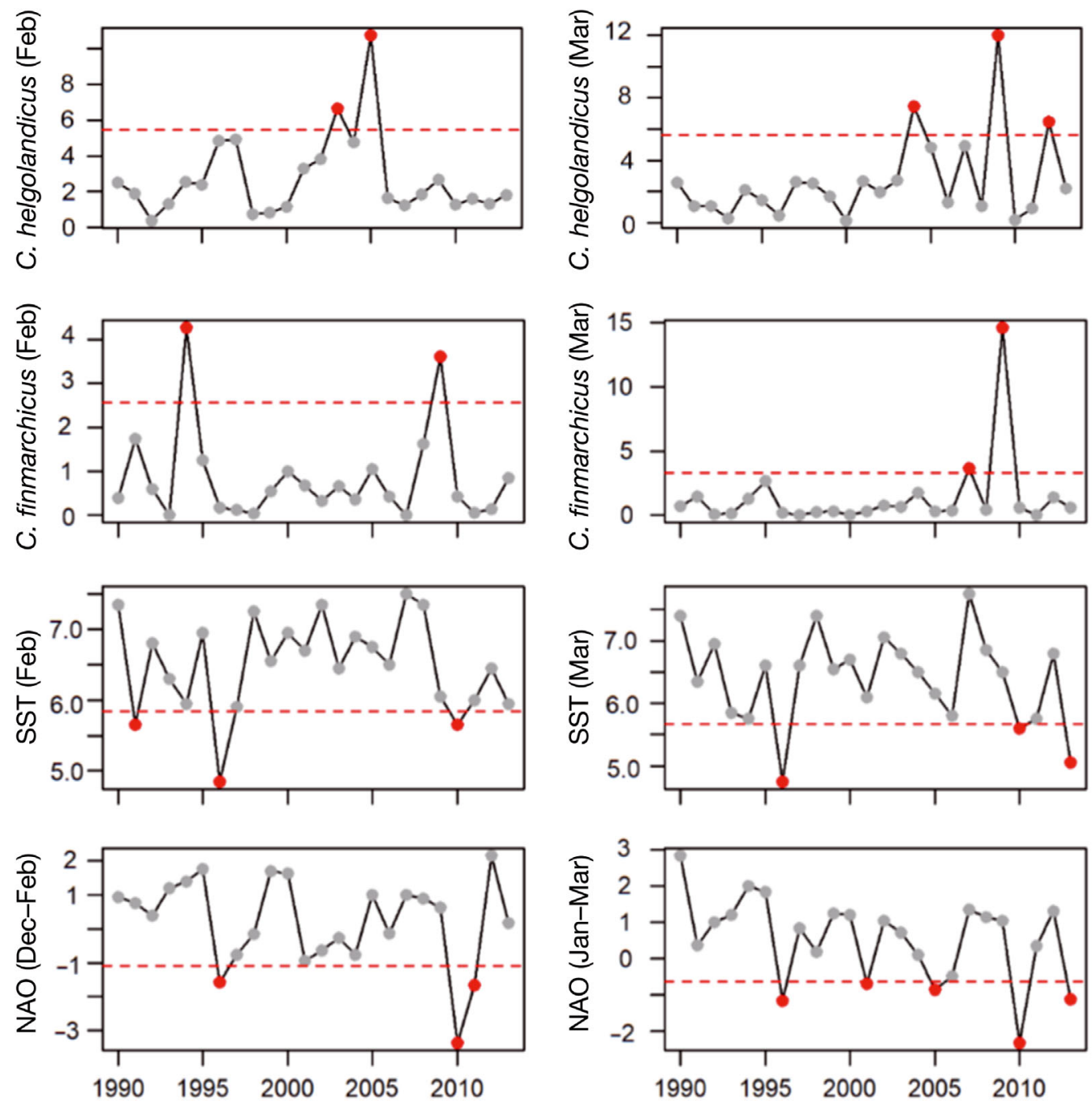

Fig. 6. Time-series of the candidate recruitment predictors for February (left column) and March (right column). Note that in case of the North Atlantic Oscillation (NAO), we applied an early (December to February) and a late (January to March) winter index, as opposed to selecting single months. The red bullet points highlight the years expected to result in highly favourable conditions for sandeel larvae survival (i.e. extending beyond the time-series mean \pm 1 SD, as indicated by a horizontal dashed line). Note that while high values of Calanus finmarchicus and C. helgolandicus are expected to represent favourable conditions, the opposite is true for NAO and sea surface temperature (SST; see 'Materials and methods' for details) 
and March and the 'retention' sub-cluster in February (in March the PCA could not distinguish between 'advection' and 'retention' flow types). Considering February in isolation, 7 out of the 24 years analysed were allocated to the cluster of negative flow regimes. However, 2 of these years were classified as 'stagnant' or 'shifting flow' and not 'retention' (in the sub-clusters) and thus whether all 7 years correspond to a reversed (clockwise) circulation on a regional scale (as in 1996) is not clear from the present results.

The schematic illustration by Sündermann \& Pohlmann (2011) of the overall circulation in the North Sea suggested 5 possible patterns, of which Kauker \& von Storch (2000) provided the most detailed description presented by a 15 yr simulation (1979-1993) using the European Centre of Medium-Range Weather Forecast reanalysis and an ocean circulation model. Here the dominant regime displayed a circulation pattern of large gyres circulating either in a counterclockwise or clockwise direction resulting from northeasterly and southwesterly winds, respectively. In line with our findings, clockwise rotations, represented by negative associated flow regimes in our data, are relatively unusual, taking place only $15 \%$ of the time (and in $22 \%$ of the trajectories analysed in our study). In comparison, clockwise directions occur $30 \%$ of the time. The 'stagnant flow' observed in our study was also identified by Kauker \& von Storch (2000) and, as in our study, these were also relatively rare $(10 \%$ in their study and $6 \%$ in our study). Kauker \& von Storch (2000) also pointed out that it was rare for regimes to last for longer periods, and only $20 \%$ persisted for $>5 \mathrm{~d}$. Some of the flows that they characterized as stagnant may therefore be comparable to what we refer to as 'shifting flow' (which we observed in $6 \%$ of the trajectories analysed). They also described a fourth intermediate type of circulation, which occurred $45 \%$ of the time, and the full nature of which we may not have captured within our study design. In this type, northwesterly or southerly winds produced bipolar circulation structures, shifting between southern and northern parts of the North Sea, which might be translated to either 'shifting flow' or 'retention' in our case.

Another remarkable pattern emerging from the present analysis was that during the first half of the time-series (1990 to ca. 2002), flow regimes of the 'advection' type dominated in February, whereas in the latter half of the time-series, flow regimes of the 'retention' type prevailed. Such an indication of an oceanographic regime shift is striking, in particular because a series of other studies have documented recent biological regime shifts in the North
Sea, such as shifts in the zooplankton species composition and reduced growth and recruitment of planktivorous fish, including sandeel (e.g. Reid et al. 2001, Beaugrand 2004, Clausen et al. 2018, Lindegren et al. 2018). However, these shifts typically occurred around 1990 (plus/minus several years), which represents the beginning of the time-series analysed in the present study, and therefore prevented us from aligning the findings from previous regime-shift studies with our data.

\section{Flow regimes in relation to sandeel recruitment and first feeding}

All 4 good recruitment years (i.e. unusually strong year-classes, see definition of 'good' in 'Materials and methods') coincided with negative flow regimes in February (only 2 in March), suggesting that the flow regimes in February, rather than in March, determine the fate of sandeel larvae on the DB. In the present study, otolith-based hatch dates were mainly confined to March, which corroborates similar studies from nearby sandeel populations (Shetland Islands and Firth of Forth), showing peak hatching in the same month (Wright \& Bailey 1996, Régnier et al. 2017). In contrast, the CPR survey also captured substantial numbers of sandeel larvae on the DB in February (Lynam et al. 2013), indicating that the otolith-based approach may be biased toward relatively late hatch dates. With this in mind, a closer inspection of the hatch date distributions revealed a heavy tail into February in 2009, which happened to coincide with a negative flow regime and the second largest recruitment event in the time-series. In fact, Wright \& Bailey (1996) also observed a similar extended tail in the 1990 hatch data distributions, which coincided with a large year class (Poloczanska et al. 2004). Hence, we suggest that negative flow regimes in February facilitate better first-feeding conditions and survival of the earliest larvae, creating the extended tails that we observed in the otolith-based hatch date distributions. This view is in line with Arnott \& Ruxton (2002), suggesting a strong link between year-class strength and survival of early larval stages in February (and not March). Unfortunately, we only had otoliths from 3 years in our possession. A more complete comparison of the timing of first feeding and recruitment was therefore not possible. A comparison of the oceanographic conditions within the firstfeeding period each year (instead of fixed windows, February and March) would also have been useful. 


\section{Utility of flow regime and other environmental descriptors in probabilistic forecasts}

On several occasions, Calanus finmarchicus has been highlighted as an important indicator of sandeel recruitment (Arnott \& Ruxton 2002, van Deurs et al. 2009, Lindegren et al. 2018). This link is based on correlations between $C$. finmarchicus abundance in February and sandeel recruitment, and has been explained by the potential naupliar production in February, when the overall zooplankton concentration is at its lowest (Arnott \& Ruxton 2002). However, the present study revealed that, while the 2 best $C$. finmarchicus years coincided with good recruitment years, other recruitment spikes occurred in very poor C. finmarchicus years (i.e. 1996). In comparison, recruitment never occurred outside a negative flow regime in February. These findings suggest that sandeel larvae do not rely entirely on C. finmarchicus for survival, as previously hypothesized. Instead, it may be that sandeel recruitment and the retention of $C$. finmarchicus near the DB are both favoured by a negative associated flow regime. Planque \& Batten (2000) explained the very low number of $C$. finmarchicus recorded by the CPR in the North Sea in 1996 by the fact that there was an unusually small C. finmarchicus population in the same year in the North Atlantic. However, it is counterintuitive that distinct $C$. finmarchicus spikes occur in negative flow regimes, given the consensus hypothesis that $C$. finmarchicus drift in a south-easterly direction into the North Sea in the first quarter of the year through the Orkney-Shetland channel and the Norwegian trench (Gallego et al. 1999, Madden et al. 1999). One plausible explanation could simply be that the surface water flow in the central North Sea is largely disconnected from the deep inflow events (below $150 \mathrm{~m}$ ) responsible for transporting C. finmarchicus into the North Sea (Reid et al. 2003, Jónasdóttir \& Koski 2011). Reid et al. (2003) also showed that the deep water inflow $(<150 \mathrm{~m})$ is negatively correlated to the inflow in the upper water column $(0-150 \mathrm{~m})$. Hence, the correlation between surface flow on top of the DB and deep inflow events is likely to be weak. Recently, Régnier et al. (2017) presented $C$. helgolandicus as a more important copepod species in relation to the year-class strength of sandeel west of the DB. This is with good reason, as C. helgolandicus has become the dominant Calanus species in the North Sea in recent decades, presumably due to climate change (Fromentin \& Planque 1996, Hinder et al. 2014). However, in relation to the DB, we found no matches between years with large numbers of $C$. helgolandicus and years with good sandeel recruitment.
Why did SST and NAO coincide poorly with recruitment in the present study, when previous studies have shown significant relationships in timeseries correlations (Arnott \& Ruxton 2002, Lindegren et al. 2018)? The explanation regarding SST may already have been provided by Lindegren et al. (2018), who described how SST defines the recruitment trends, but not the extreme recruitment events. Therefore, while SST could potentially be used to inform managers about productivity regimes (Clausen et al. 2018, Lindegren et al. 2018), it has little value in relation to short-term forecasts of fishing opportunities, in particular for stocks displaying boom-and-bust dynamics (Stocker \& Hilborn 1981, de Moor et al. 2011). NAO has been linked to C. finmarchicus regimes on a decadal time scale (Planque \& Taylor 1998, Heath et al. 1999), and some degree of correlation between sandeel recruitment and winter NAO has also been reported (Arnott \& Ruxton 2002). NAO influences the North Sea circulation usually with a positive relationship, where stronger westerly winds amplify the general cyclonic circulation during $\mathrm{NAO}+$ phases. Nonetheless, positive phases also seem to favour wind conditions that could lead to circulation reversals on weekly and monthly scales (Mathis et al. 2015), which limits the chance of finding any robust correlations between NAO and local circulation patterns at the DB. It is therefore not surprising to find that NAO is a poor predictor of the inter-annual variation in sandeel recruitment.

As mentioned above, all good recruitment events coincided with a negative flow regime in February. In contrast, when a positive flow regime is observed in February, the prediction is that the recruitment will always be moderate to low. However, 3 out of the 7 years $(1991,2007$, and 2010) assigned to the cluster of negative flow regimes in February were not good recruitment years. In this respect, it is important to mention that 1991 and 2007 represent peaks in the recruitment time-series, although they did not classify as 'good recruitment' years under the criteria set in our study. Furthermore, although 1991 had a flow trajectory almost identical to that of other good recruitment years, it also showed a unique signature of total stagnation in March, which could explain why good recruitment failed to take place in 1991 despite suitable conditions in February (i.e. assuming that stagnation is suboptimal for larval growth and survival). The year 2007 was characterized by a low spawning biomass (less than the time-series average minus $1 \mathrm{SD}$ ), suggesting some influence from the S-R relationship. Strong density-dependent regulation induced by $1 \mathrm{yr}$ old fish in the population has been 
proposed in former studies (e.g. van Deurs et al. 2009, Lindegren et al. 2018). Numbers of age-1 fish were about average or below in 1991 and 2007. However, in 2010 the second highest number of age-1 fish in the study period was recorded, potentially explaining the poor recruitment in this year (time-series of spawning stock biomass and numbers of age-1 fish are available in ICES 2016b).

\section{A recruitment hypothesis}

While the consensus in the literature regarding sandeels is that they appear to have strong links with specific prey types, coupling the 'match-mismatch' hypothesis (Cushing 1969, 1975, 1990) to mainly the relative large Calanus copepods advected into the North Sea (e.g. Arnott \& Ruxton 2002, Régnier et al. 2017), we suggest considering alternative hypotheses, such as the 'weak link/strong filter' hypothesis proposed by Runge (1988), or the 'Stable Ocean' and 'Optimal Environmental Window' theories (Lasker 1978, Cury \& Roy 1989). Applying these to the sandeel case would imply that the link to Calanus copepods is relatively weak, and that the inter-annual variability of sandeel recruitment is instead filtered by smaller copepod species and other microzooplankton and strong links to the local physical environment, defining the small-scale trophodynamics experienced by the fish larvae. Previous reports of diet shifts in sandeel larvae to match available prey (de Figueiredo et al. 2005, 2007) and a connection between the timing of the peak in sandeel larvae abundance and the onset of phytoplankton production (Sherman et al. 1984, Monteleone \& Peterson 1986, Malzahn \& Boersma 2009) are in support of this hypothesis, because trophic flexibility and tight bonds to primary production disfavour a strong link to specific prey types, such as Calanus.

The present results not only indicate a strong link to the physical environment, but also suggest the importance of the sequence of favourable and unfavourable oceanographic conditions taking place within a critical recruitment window. For example, in the occasional year where favourable conditions are already established at the beginning of February, a whole month is added to the critical recruitment window, which in a 'normal' year does not start until March, where environmental conditions are much more stable from year to year (Wright \& Bailey 1996, Lynam et al. 2013, Régnier et al. 2017). Therefore, the longer the sequence of favourable oceanographic conditions is, the larger is the recruitment (Fig. 7).
If favourable oceanographic winter (February) conditions occur often enough, early hatching may even be favoured, as it extends the duration of the growth period and increases the probability (relative to larvae hatching in March or April) that the critical threshold size is reached before winter (van Deurs et al. 2011). Studies on the yolk sac period in sandeel may support to this view. The yolk sac provides nutrition for sandeel larvae during the first $\sim 12 \mathrm{~d}$ after hatching (Wright 1993), which helps them cope with low food availability for as much as 2 wk (Buckley et al. 1984, Régnier et al. 2017). At the same time, all winter-hatching sandeel are apparently capable of feeding prior to yolk sac absorption (Yamashita \& Aoyama 1985), enabling advantageous utilization of an extended growth period whenever oceanographic conditions are already favourable in February.

The remaining question is: What does 'favourable oceanographic conditions' mean? In the search for direct causal relationships, we suggest that larval retention and advection processes on the DB are important. The flow regimes associated with unusually strong year-classes are characterized by either bidirectional flow or relatively limited net flow in a northerly direction in February (in contrast to a relatively strong net flow in a southerly direction, which prevails in most years). We hypothesize that this flow regime promotes dominance of southern water masses (e.g. from the Southern Bight, German Bight, and Wadden Sea), where primary production is highest in February (Joint \& Pomroy 1993, Moll 1998). At the same time, the relatively limited net flow over the DB ensures larval retention and concentrates microzooplankton and phytoplankton for the early hatching larvae to feed on (Malzahn et al. 2007, Malzahn \& Boersma 2009). These speculations are in line with earlier model simulations identifying the optimal sandeel hatching time to be February in the southeastern North Sea (Gurkan et al. 2013) and the DB to be a location where retention dominates over advection, facilitating perfect conditions for accumulating food and retaining sandeel larvae near suitable settlement habitats (Christensen et al. 2008).

Despite our efforts to identify and discuss possible causal relationships, the underlying mechanisms remain unclear, and the data presented here were not designed to support strong conclusions about anything other than the striking concurrence between unusually strong sandeel year-classes and negative flow regimes. We therefore encourage further research, pursuing the hypotheses and ideas developed in this study. 


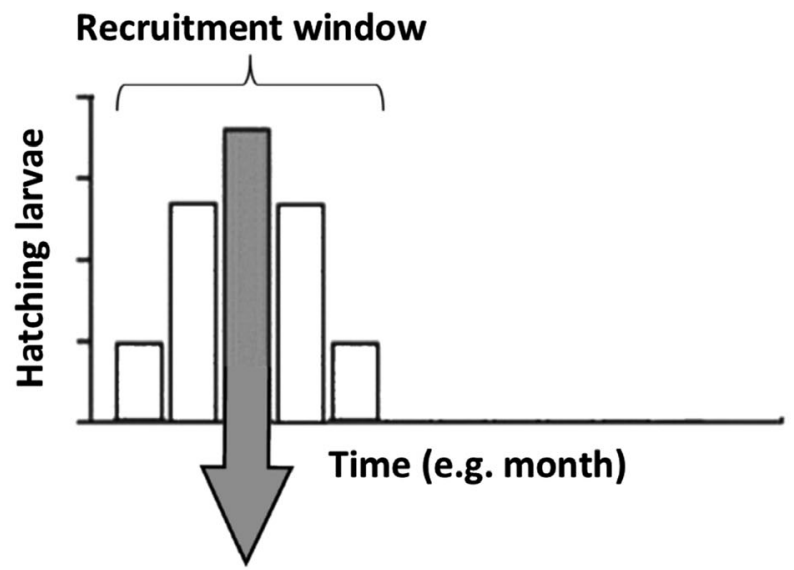

\section{Sequence and/or combination of}

\section{oceanographic events over time}

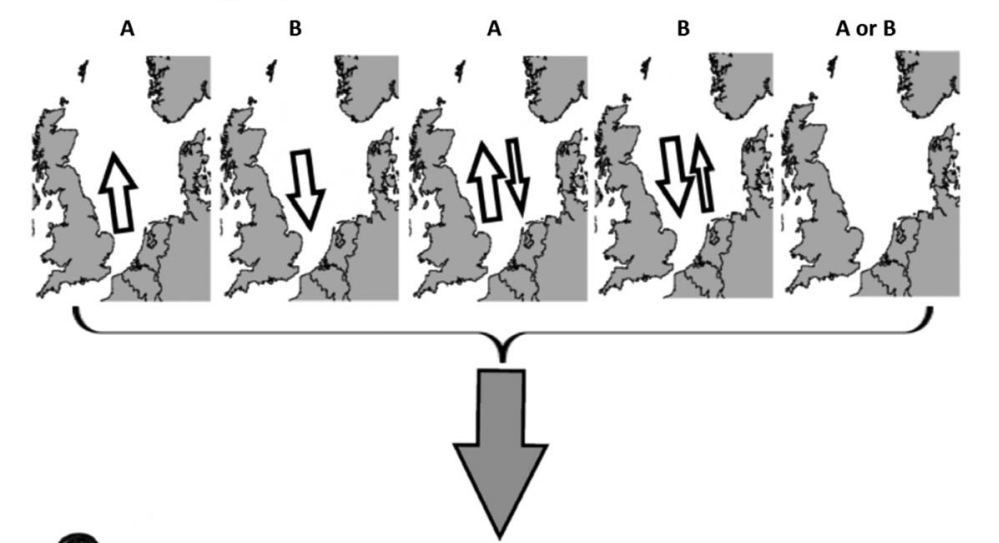

Conclusions and prospects of using oceanographic data to forecast stock productivity

Here we have demonstrated, for the first time, how internal North Sea circulation patterns can be used to predict fish recruitment in the North Sea. We found that good sandeel recruitment occurred only when negative flow regimes prevailed in February (and is most likely to occur in the 'retention' type of negative flow regimes). It is also plausible that these negative flow regimes can be translated into reversals of the predominant North Sea circulation pattern (i.e. changed from clockwise to counterclockwise), although this may be a rather oversimplistic description of complex oceanographic processes, requiring further validation studies using, for example, North-Sea-wide 2D flow fields. Moreover, other candidate drivers, such as chlorophyll (Bakun 2006), might provide further insight into the mechanistic understanding behind these large year-classes. We also found indications of a previously unnoticed oceanographic regime shift in

Fig. 7. 'Recruitment window' hypothesis. Vertical grey arrows signify the order of events in the flowchart. The recruitment window represents the critical period where hatching and first feeding larvae are present. Within this window, it is the sequence of oceanographic events (i.e. flow regimes) that determines growth and survival of the larvae (i.e. flow regimes define the foraging arena and/or larval retention processes). For example, a given sequence can be comprised of both optimal conditions (labelled 'A') and poor conditions ('B'), where poor conditions lead to dramatically impaired survival (i.e. $\leq 10 \%$ of the survival experienced when conditions are optimal; see Houde 2008 regarding the scaling of larval mortality). In the flow chart, the different types of flow regimes found in the present study are used to exemplify optimal and poor conditions (illustrated with arrows and labelled A \& B). Note that in stagnant flow regimes (flow regime on the far right) it is unclear from the present results whether this translates into optimal or poor conditions for the larvae. In the end, total recruitment is approximately proportional to the ratio between optimal and poor conditions within the recruitment window 
the North Sea taking place around 2002, which also warrants further investigation. Lastly, we recognise that a relatively coarse resolution in ocean models (such as in the model used here) can lead to an underestimation of the volume transport, making it easier for wind forcing to affect surface flow (Pätsch et al. 2017). Hence, we recommend that future studies use a higher horizontal model resolution.

The use of oceanographic data in recruitment forecasts is still very limited (e.g. Myers 1998, Payne et al. 2017), despite the fact that oceanographic and meteorological data have proven useful in understanding recruitment dynamics of some of the largest fish stocks in the world. For example, there is a link between productivity of Pacific sardine and winddriven upwelling systems off the coast of Central America and coupling between certain physical conditions of the Norwegian Coastal Current and the survival and growth of Norwegian spring spawning herring larvae drifting toward the nursery grounds in the Barents Sea (Rykaczewski \& Checkley 2008, Skagseth et al. 2015). In this study, we have demonstrated that information about local flow regimes outperforms other previously considered recruitment predictors with respect to forecasting the most extreme recruitment events. Our approach differs from many other time-series studies of fish recruitment by being probabilistic (i.e. the RR approach) and focussing on the anomalies (i.e. the most extreme recruitment events) rather than on the average trends. This approach may be useful in regions with highly variable oceanographic conditions. Lastly, we propose a hypothesis for sandeel recruitment and its relation to physical oceanography, which we hope will inspire future research (Fig. 7).

While our study has quantified a probabilistic link between flow conditions and recruitment, there are additional considerations which must be addressed before such a relationship can be applied in stock forecasting. These include verification of the proposed recruitment hypothesis and a demonstration that such a forecast will effectively improve the stock advice with respect to forecast accuracy and stakeholder needs.

Acknowledgements. The contributions by M.v.D., S.J., and B.R.M. in this investigation were supported in part by the COFASP ERA-NET partners, which has received funding from the European Union's Seventh Framework Program for research, technological development, and demonstration under grant agreement no. 321553 (GOFORIT project), and by the national funding agency of Denmark. M.v.D., O.H., and A.C. were supported by the European Fisheries Foundation (33113-B-16-080). Lastly, we thank 3 anonymous reviewers for providing very constructive and helpful feedback.

\section{LITERATURE CITED}

Abdi H, Williams LJ (2010) Principal component analysis. Wiley Interdiscip Rev Comput Stat 2:433-459

Arnott SA, Ruxton GD (2002) Sandeel recruitment in the North Sea: demographic, climatic and trophic effects. Mar Ecol Prog Ser 238:199-210

Bakun A (2006) Wasp-waist populations and marine ecosystem dynamics: navigating the 'predator pit' topographies. Prog Oceanogr 68:271-288

Beaugrand G (2004) The North Sea regime shift: evidence, causes, mechanisms and consequences. Prog Oceanogr 60:245-262

Beaugrand G, Brander KM, Lindley JA, Souissi S, Reid PC (2003) Plankton effect on cod recruitment in the North Sea. Nature 426:661-664

Berg P, Poulsen JW (2012) Implementation details for HBM. DMI Tech Rep 12-11. Danish Meteorological Institute, Copenhagen

Bergström S (1992) The HBV model-its structure and applications. SMHI Rep Hydrol 4. Swedish Meteorological and Hydrological Institute, Norrköping

Berntsen J, Skagen DW, Svendsen E (1994) Modelling the transport of particles in the North Sea with reference to sandeel larvae. Fish Oceanogr 3:81-91

Brown J, Hill AE, Fernand L, Horsburgh KJ (1999) Observations of a seasonal jet-like circulation at the central North Sea cold pool margin. Estuar Coast Shelf Sci 48:343-355

Buckley LJ, Turner SI, Halavik TA, Smigielski AS, Drew SM, Laurence GC (1984) Effects of temperature and food availability on growth, survival, and RNA-DNA ratio of larval sand lance (Ammodytes americanus). Mar Ecol Prog Ser 15:91-97

* Burrow JF, Horwood JW, Pitchford JW (2011) The importance of variable timing and abundance of prey for fish larval recruitment. J Plankton Res 33:1153-1162

Canuto VM, Howard A, Cheng Y, Dubovikov MS (2002) Ocean turbulence. Part II: Vertical diffusivities of momentum, heat, salt, mass, and passive scalars. J Phys Oceanogr 32:240-264

Cattell RB (1966) The scree test for the number of factors. Multivariate Behav Res 1:245-276

Chessel D, Dufour AB, Thioulouse J (2004) The ade4 package. I. One-table methods. R News 4:5-10

* Christensen A, Daewel U, Jensen H, Mosegaard H, St. John M, Schrum C (2007) Hydrodynamic backtracking of fish larvae by individual-based modelling. Mar Ecol Prog Ser 347:221-232

Christensen A, Jensen H, Mosegaard H, St. John M, Schrum C (2008) Sandeel (Ammodytes marinus) larval transport patterns in the North Sea from an individual-based hydrodynamic egg and larval model. Can J Fish Aquat Sci 65:1498-1511

Clausen LW, Rindorf A, van Deurs M, Dickey-Collas M, Hintzen NT (2018) Shifts in North Sea forage fish productivity and potential fisheries yield. J Appl Ecol 55:1092-1101

Collie JS, Botsford LW, Hastings A, Kaplan IC and others (2016) Ecosystem models for fisheries management: finding the sweet spot. Fish Fish 17:101-125

* Conway D, Coombs SH, Smith C (1997) Vertical distribution of fish eggs and larvae in the Irish Sea and southern North Sea. ICES J Mar Sci 54:136-147

* Cury P, Roy C (1989) Optimal environmental window and pelagic fish recruitment success in upwelling areas. Can J Fish Aquat Sci 46:670-680 
Cushing DH (1969) The regularity of the spawning season of some fishes. ICES J Mar Sci 33:81-92

Cushing DH (1975) Marine ecology and fisheries. Cambridge University Press, Cambridge

Cushing DH (1990) Plankton production and year-class strength in fish populations: an update of the match/mismatch hypothesis. Adv Mar Biol 26:249-293

de Figueiredo GM, Nash RDM, Montagnes DJS (2005) The role of the generally unrecognised microprey source as food for larval fish in the Irish Sea. Mar Biol 148:395-404

de Figueiredo GM, Nash RDM, Montagnes DJS (2007) Do protozoa contribute significantly to the diet of larval fish in the Irish Sea? J Mar Biol Assoc UK 87:843-850

de Moor CL, Butterworth DS, De Oliveira JAA (2011) Is the management procedure approach equipped to handle short-lived pelagic species with their boom and bust dynamics? The case of the South African fishery for sardine and anchovy. ICES J Mar Sci 68:2075-2085

Dick S, Kleine E, Müller-Navarra S, Klein H, Komo H (2001) The operational circulation model of BSH (BSHcmod): model description and validation. Bundesamt für Seeschiffaahrt und Hydrographie, Hamburg

Fogarty MJ, Sissenwine MP, Cohen EB (1991) Recruitment variability and the dynamics of exploited marine populations. Trends Ecol Evol 6:241-246

Fréon P, Cury P, Shannon L, Roy C (2005) Sustainable exploitation of small pelagic fish stocks challenged by environmental and ecosystem changes: a review. Bull Mar Sci 76:385-462

Fromentin JM, Planque B (1996) Calanus and environment in the eastern North Atlantic. II. Influence of the North Atlantic Oscillation on C. finmarchicus and C. helgolandicus. Mar Ecol Prog Ser 134:111-118

Fujiwara T, Nakata H, Tanda M, Karakawa J (1990) Biological and physical parameters of the population dynamics of sand eel larvae in the eastern Seto Inland Sea. Bull Jpn Soc Sci Fish 56:1029-1037

Gallego A, Mardaljevic J, Heath MR, Hainbucher D, Slagstad D (1999) A model of the spring migration into the North Sea by Calanus finmarchicus overwintering off the Scottish continental shelf. Fish Oceanogr 8:107-125

Gallego A, Heath MR, Cook B (2004) The origin and destination of sandeel larvae sampled in the northern North Sea: bio-physical modelling simulation results. ICES CM 2004/P:09. ICES, Copenhagen

* Greene CH, Pershing AJ (2003) The flip-side of the North Atlantic Oscillation and modal shifts in slope-water circulation patterns. Limnol Oceanogr 48:319-322

Gurkan Z, Christensen A, van Deurs M, Mosegaard H (2012) Growth and survival of larval and early juvenile lesser sandeel in patchy prey field in the North Sea: an examination using individual-based modeling. Ecol Model 232:78-90

Gurkan Z, Christensen A, Maar M, Møller EF, Madsen KS, Munk P, Mosegaard H (2013) Spatio-temporal dynamics of growth and survival of lesser sandeel early life-stages in the North Sea: predictions from a coupled individualbased and hydrodynamic-biogeochemical model. Ecol Model 250:294-306

* Heath MR, Backhaus JO, Richardson K, McKenzie E and others (1999) Climate fluctuations and the spring invasion of the North Sea by Calanus finmarchicus. Fish Oceanogr 8:163-176

*Hinder SL, Gravenor MB, Edwards M, Ostle C and others (2014) Multi-decadal range changes vs. thermal adapta- tion for north east Atlantic oceanic copepods in the face of climate change. Glob Change Biol 20:140-146

Hjort J (1914) Fluctuations in the great fisheries of northern Europe viewed in the light of biological research. Cons Perm Int Explor Mer Rapp P-V Réun (Dan) 20:1-228

Hjort J (1926) Fluctuations in the year classes of important food fishes. ICES J Mar Sci 1:5-38

*Houde ED (2008) Emerging from Hjort's shadow. J Northwest Atl Fish Sci 41:53-70

*Hutchings L (1992) Fish harvesting in a variable, productive environment-searching for rules or searching for exceptions? S Afr J Mar Sci 12:297-318

ICES (2016a) Herring Assessment Working Group for the Area South of $62 \mathrm{deg}$ N (HAWG). ICES CM 2016/ACOM: 07. ICES, Copenhagen

ICES (2016b) Report of the Benchmark Workshop on Sandeel (WKSand 2016). ICES CM 2016/ACOM:33. ICES, Copenhagen

ICES (2018) Herring Assessment Working Group for the Area South of $62 \mathrm{deg}$ N (HAWG). ICES CM 2018/ACOM: 07. ICES, Copenhagen

K Jensen H, Wright PJ, Munk P (2003) Vertical distribution of pre-settled sandeel (Ammodytes marinus) in the North Sea in relation to size and environmental variables. ICES J Mar Sci 60:1342-1351

Joint I, Pomroy A (1993) Phytoplankton biomass and production in the southern North Sea. Mar Ecol Prog Ser 99: 169-182

Jónasdóttir SH, Koski M (2011) Biological processes in the North Sea: comparison of Calanus helgolandicus and Calanus finmarchicus vertical distribution and production. J Plankton Res 33:85-103

Kauker F, von Storch H (2000) Statistics of 'Synoptic Circulation Weather' in the North Sea as derived from a multiannual OGCM simulation. J Phys Oceanogr 30: 3039-3049

Kristiansen T, Drinkwater KF, Lough RG, Sundby S (2011) Recruitment variability in North Atlantic cod and matchmismatch dynamics. PLOS ONE 6:e17456

ㄴacroix G, Maes GE, Bolle LJ, Volckaert FAM (2013) Modelling dispersal dynamics of the early life stages of a marine flatfish (Solea solea L.). J Sea Res 84:13-25

Lasker R (1978) The relations between oceanographic conditions and larval anchovy food in the California Current: identification of factors contributing to recruitment failure. Rapp P-V Reun Cons Int Explor Mer 173:212-230

K Leibovici DG (2010) Spatio-temporal multiway data decompositions using Principal Tensor Analysis on k-Modes: the R package PTAk. J Stat Softw 34:1-34

Lewy P, Vinther M (2004) A stochastic age-length-structured multispecies model applied to North Sea stocks. ICES CM 2004/FF:20. ICES, Copenhagen

* Lindegren M, Van Deurs M, MacKenzie BR, Worsoe Clausen L, Christensen A, Rindorf A (2018) Productivity and recovery of forage fish under climate change and fishing: North Sea sandeel as a case study. Fish Oceanogr 27: 212-221

* Lynam CP, Halliday NC, Hoffle H, Wright PJ, van Damme CJG, Edwards M, Pitois SG (2013) Spatial patterns and trends in abundance of larval sandeels in the North Sea: 1950-2005. ICES J Mar Sci 70:540-553

Madden H, Beare D, Heath MR, Fraser JG, Gallego A (1999) The spring/early summer distribution of Calanus spp. in the northern North Sea and adjacent areas. Fish Oceanogr 8:138-152 
Malzahn AM, Boersma M (2009) Trophic flexibility in larvae of two fish species (lesser sandeel, Ammodytes marinus and dab, Limanda limanda). Sci Mar 73:131-139

*Malzahn AM, Clemmesen C, Wiltshire KH, Laakmann S, Boersma M (2007) Comparative nutritional condition of larval dab Limanda limanda and lesser sandeel Ammodytes marinus in a highly variable environment. Mar Ecol Prog Ser 334:205-212

Mantzouni I, MacKenzie BR (2010) Productivity responses of a widespread marine piscivore, Gadus morhua, to oceanic thermal extremes and trends. Proc R Soc B 277:1867-1874

Mathis M, Elizalde A, Mikolajewicz U, Pohlmann T (2015) Variability patterns of the general circulation and sea water temperature in the North Sea. Prog Oceanogr 135: 91-112

Moll A (1998) Regional distribution of primary production in the North Sea simulated by a three-dimensional model. J Mar Syst 16:151-170

Monteleone DM, Peterson WT (1986) Feeding ecology of American sand lance Ammodytes americanus larvae from Long Island Sound. Mar Ecol Prog Ser 30:133-143

Myers R (1995) Recruitment of marine fish: the relative roles of density-dependent and density-independent mortality in the egg, larval, and juvenile stages. Mar Ecol Prog Ser 128:308-309

Myers RA (1998) When do environment-recruitment correlations work? Rev Fish Biol Fish 8:285-305

Myers R, Barrowman N (1996) Is fish recruitment related to spawner abundance? Fish Bull 94:707-724

Nerger L, Losa SN, Brüning T, Janssen F (2014) The HBMPDAF assimilation system for operational forecasts in the North and Baltic Seas. In: Buch E, Antoniou Y, Eparkhina D, Nolan G (eds) Operational oceanography for sustainable blue growth. Proceedings of the Seventh EuroGOOS International Conference, Lisbon, Portugal, p 337-347

Olsen EM, Ottersen G, Llope M, Chan KS, Beaugrand G, Stenseth NC (2011) Spawning stock and recruitment in North Sea cod shaped by food and climate. Proc R Soc B 278:504-510

*Pätsch J, Burchard H, Dieterich C, Gräwe U and others (2017) An evaluation of the North Sea circulation in global and regional models relevant for ecosystem simulations. Ocean Model 116:70-95

* Payne MR, Hobday AJ, MacKenzie BR, Tommasi D and others (2017) Lessons from the first generation of marine ecological forecast products. Front Mar Sci 4:289

Planque B, Batten SD (2000) Calanus finmarchicus in the North Atlantic: the year of Calanus in the context of interdecadal change. ICES J Mar Sci 57:1528-1535

* Planque B, Taylor AH (1998) Long-term changes in zooplankton and the climate of the North Atlantic. ICES J Mar Sci 55:644-654

Poloczanska ES, Cook RM, Ruxton GD, Wright PJ (2004) Fishing vs. natural recruitment variation in sandeels as a cause of seabird breeding failure at Shetland: a modelling approach. ICES J Mar Sci 61:788-797

Proctor R, Wright PJ, Everitt A (1998) Modelling the transport of larval sandeels on the north-west European shelf. Fish Oceanogr 7:347-354

Régnier T, Gibb FM, Wright PJ (2017) Importance of trophic mismatch in a winter-hatching species: evidence from lesser sandeel. Mar Ecol Prog Ser 567:185-197

Reid PC, Holliday NP, Smyth TJ (2001) Pulses in the eastern margin current and warmer water off the north west
European shelf linked to North Sea ecosystem changes. Mar Ecol Prog Ser 215:283-287

Reid PC, Edwards M, Beaugrand G, Skogen M, Stevens D (2003) Periodic changes in the zooplankton of the North Sea during the twentieth century linked to oceanic inflow. Fish Oceanogr 12:260-269

* Ricker WE (1954) Stock and recruitment. J Fish Res Board Can 11:559-623

* Runge JA (1988) Should we expect a relationship between primary production and fisheries? The role of copepod dynamics as a filter of trophic variability. Hydrobiologia 167-168:61-71

Krykaczewski RR, Checkley DM (2008) Influence of ocean winds on the pelagic ecosystem in upwelling regions. Proc Natl Acad Sci USA 105:1965-1970

* Schwartzlose RA, Alheit J, Bakun A, Baumgartner TR and others (1999) Worldwide large-scale fluctuations of sardine and anchovy populations. S Afr J Mar Sci 21: 289-347

* She J, Berg P, Berg J (2007) Bathymetry impacts on water exchange modelling through the Danish Straits. J Mar Syst 65:450-459

Sherman K, Smith W, Morse W, Berman M, Green J, Ejsymont L (1984) Spawning strategies of fishes in relation to circulation, phytoplankton production, and pulses in zooplankton off the northeastern United States. Mar Ecol Prog Ser 18:1-19

Skagseth Ø, Slotte A, Stenevik EK, Nash RDM (2015) Characteristics of the Norwegian Coastal Current during years with high recruitment of Norwegian spring spawning herring (Clupea harengus L.). PLOS ONE 10: e0144117

Skern-Mauritzen M, Ottersen G, Handegard NO, Huse G, Dingsør GE, Stenseth NC, Kjesbu OS (2016) Ecosystem processes are rarely included in tactical fisheries management. Fish Fish 17:165-175

Smagorinsky J (1963) General circulation experiments with primitive equations. I. The basic experiment. Mon Weather Rev 91:99-164

Solow AR (2002) Fisheries recruitment and the North Atlantic Oscillation. Fish Res 54:295-297

* Stocker M, Hilborn R (1981) Short-term forecasting in marine fish stocks. Can J Fish Aquat Sci 38:1247-1254

Sündermann J (2003) The changing North Sea: knowledge, speculation and new challenges. Oceanologia 45: $247-259$

* Sündermann J, Pohlmann T (2011) A brief analysis of North Sea physics. Oceanologia 53:663-689

* Szuwalski CS, Vert-Pre KA, Punt AE, Branch TA, Hilborn R (2015) Examining common assumptions about recruitment: a meta-analysis of recruitment dynamics for worldwide marine fisheries. Fish Fish 16:633-648

* Tiessen MCH, Fernard L, Gerkema T, Van Der Molen J, Ruardij P, Van Der Veer HW (2014) Numerical modelling of physical processes governing larval transport in the southern North Sea. Ocean Sci 10:357-376

*Ulrich C, Hemmer-Hansen J, Boje J, Christensen A, Hüssy K, Sun H, Clausen LW (2017) Variability and connectivity of plaice populations from the Eastern North Sea to the Baltic Sea. II. Biological evidence of population mixing. J Sea Res 120:13-23

*van Deurs M, van Hal R, Tomczak MT, Jónasdóttir SH, Dolmer P (2009) Recruitment of lesser sandeel Ammodytes marinus in relation to density dependence and zooplankton composition. Mar Ecol Prog Ser 381:249-258 
van Deurs M, Hartvig M, Steffensen JF (2011) Critical threshold size for overwintering sandeels (Ammodytes marinus). Mar Biol 158:2755-2764

Vert-pre KA, Amoroso RO, Jensen OP, Hilborn R (2013) Frequency and intensity of productivity regime shifts in marine fish stocks. Proc Natl Acad Sci USA 110: 1779-1784

Walters CJ, Collie JS (1988) Is research on environmental factors useful to fisheries management? Can J Fish Aquat Sci 45:1848-1854

Ward JH (1963) Hierarchical grouping to optimize an objective function. J Am Stat Assoc 58:236-244
Wilson R, Crouch EA (1987) Risk assessment and comparisons: an introduction. Science 236:267-270

*Wright PJ (1993) Otolith microstructure of the lesser sandeel, Ammodytes marinus. J Mar Biol Assoc UK 73: 245-248

* Wright PJ, Bailey MC (1996) Timing of hatching in Ammodytes marinus from Shetland waters and its significance to early growth and survivorship. Mar Biol 126:143-152

*Yamashita Y, Aoyama T (1985) Hatching time, yolk sac absorption, onset of feeding, and early growth of the Japanese sand eel Ammodytes personatus. Bull Jpn Soc Sci Fish 51:1777-1780

Appendix. Additional information on the PCA
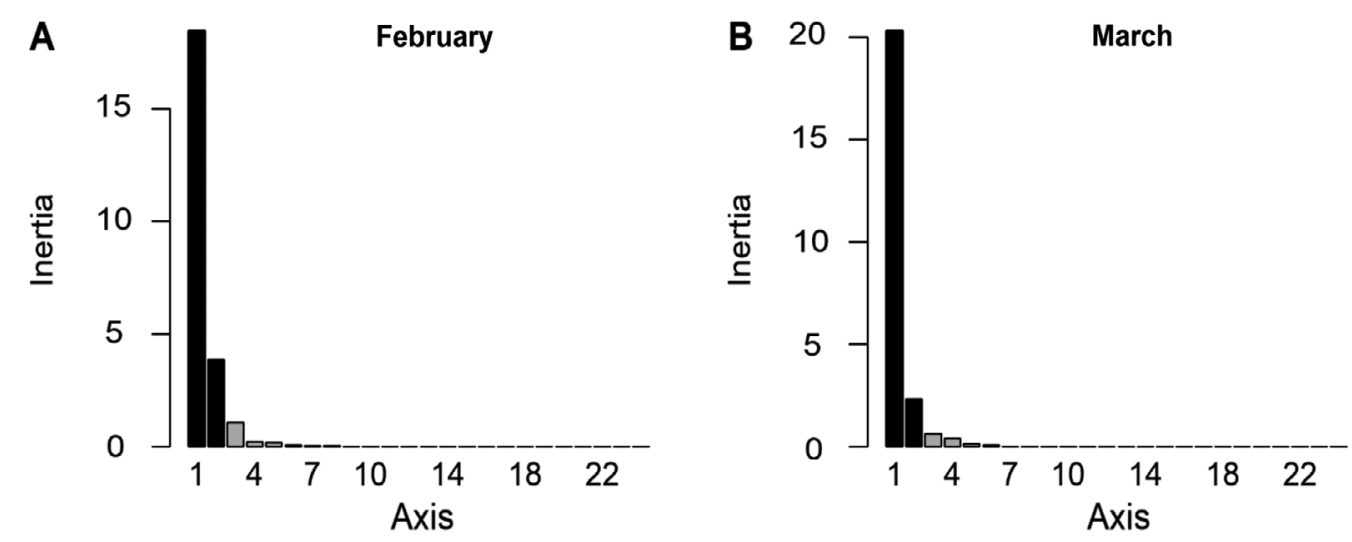

Fig. A1. Scree plots of eigenvalues ordered from largest to the smallest; (A) February, (B) March. The number of principal components (PCs) is determined at the point beyond which the remaining eigenvalues are all relatively small and of comparable size. Black bars signify PCs retained for PCAs

\section{A February}

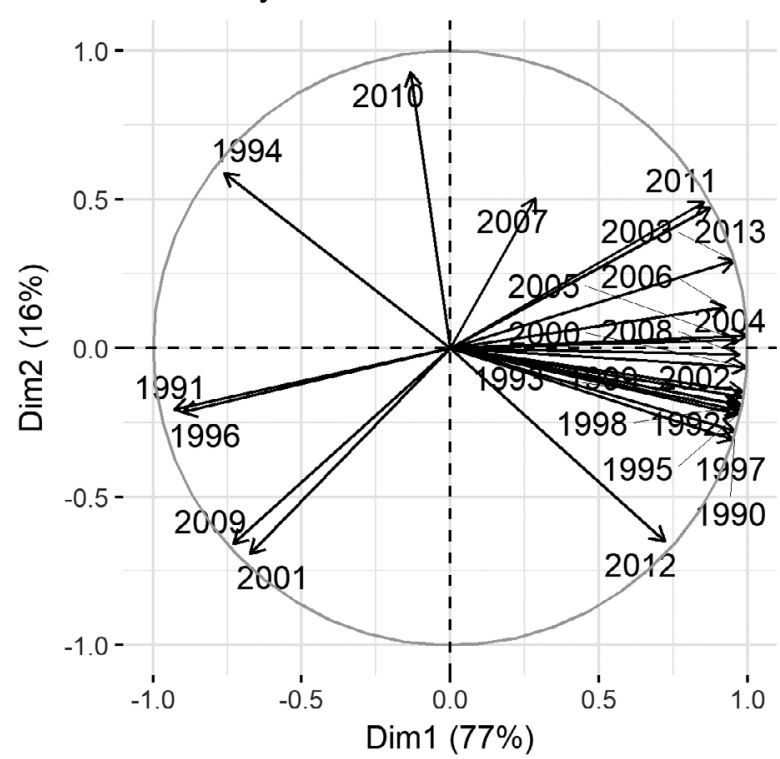

B March

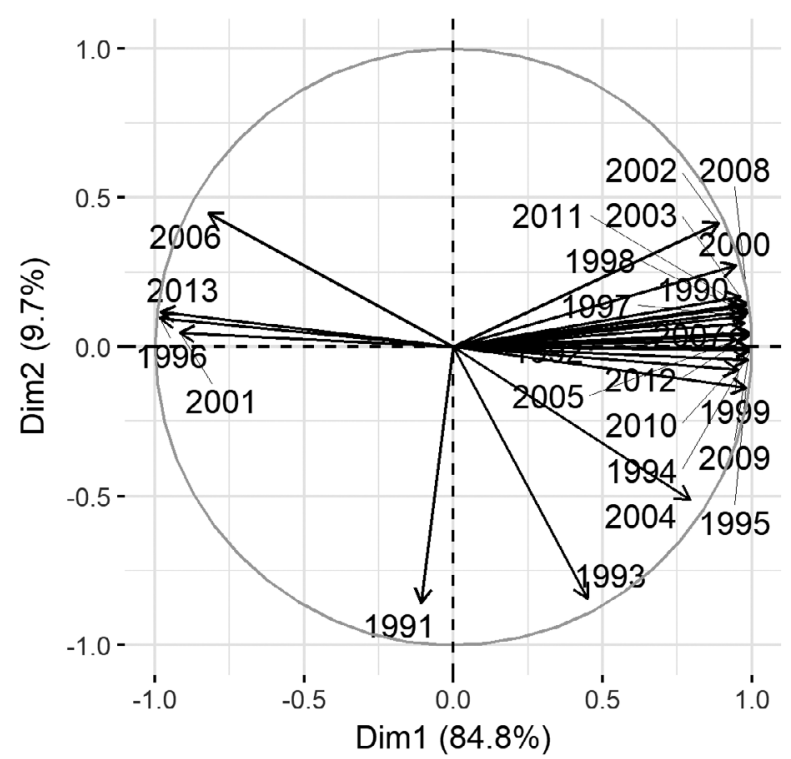

Fig. A2. Correlation circles (A, February; B, March) showing correlations between years and principal components, PC1 (i.e Dim1) and PC2 (i.e. Dim2), where correlated years are grouped together. The distance between arrows and the origin measures the quality of the years on the factor map. Variables that are away from the origin are well represented on the factor map 

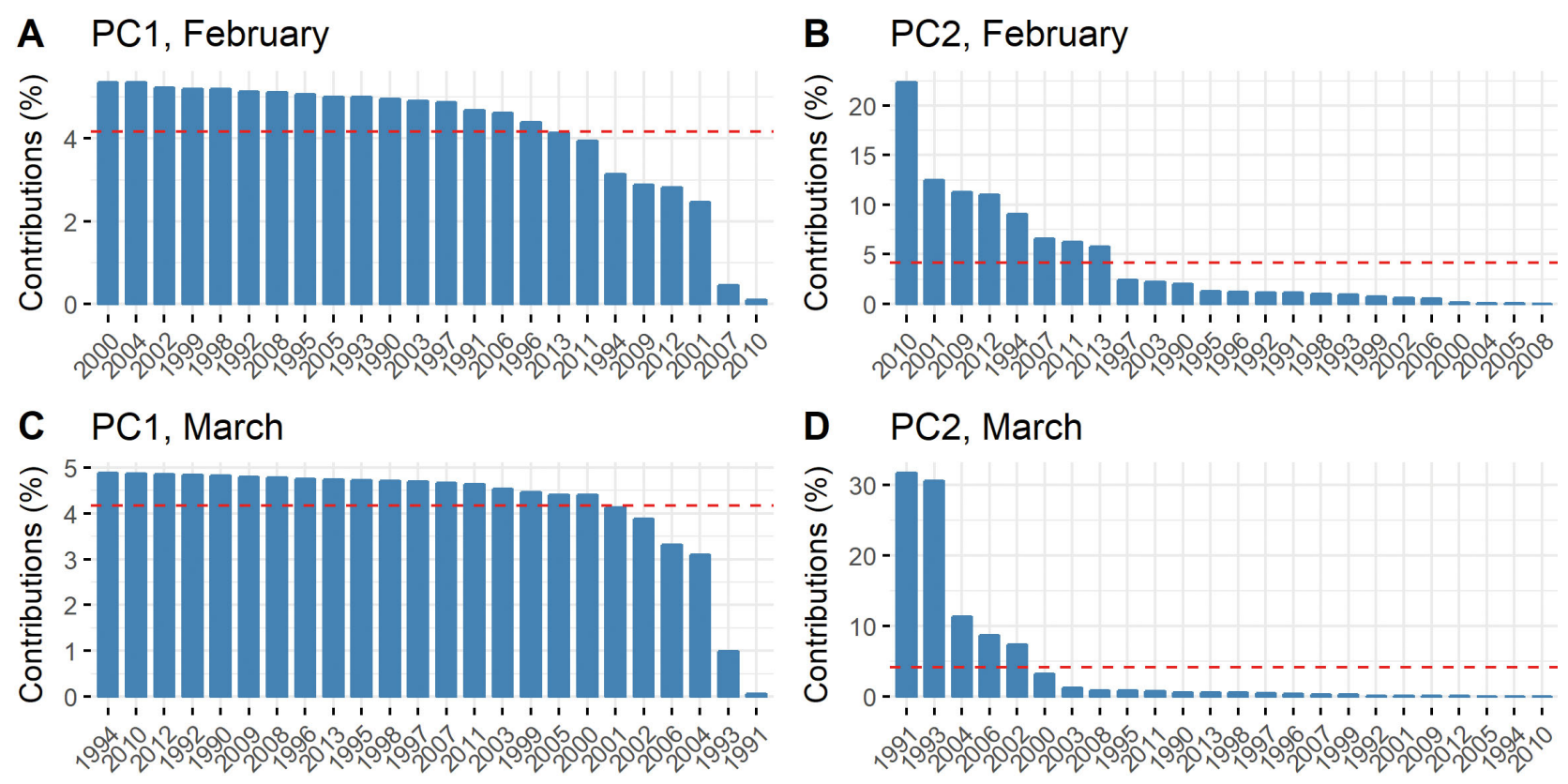

Fig. A3. Total contribution of years to principal components PC1 and PC2 in February and March. Contributions of variables in accounting for the variability in a given PC are expressed in percentage (\%). The red dashed line on the graph indicates the expected average contribution

Editorial responsibility: Alejandro Gallego, Aberdeen, UK
Submitted: April 17, 2018; Accepted: October 11, 2018 Proofs received from author(s): November 16, 2018 